\title{
Fracture analysis on flywheel bolt of ISG motor for hybrid bus
}

\author{
Youming Tang ${ }^{1, a}$, Zonghui Yan ${ }^{2, b}$, Guibin Sun ${ }^{1, c}$, Yi Zhang ${ }^{1, d}$ and Kun Dong ${ }^{1, e}$ \\ ${ }^{1}$ Fujian Institute of New Energy Vehicles and Safety Technology, Xiamen University of Technology, \\ Xiamen, Fujian, P.R.China \\ ${ }^{2}$ Fujian Fugong Power Technology Co., Ltd., Xiamen, Fujian, P.R.China \\ atangym1981@163.com, byanzh@fghev.com, ${ }^{c} 2012110803 @ x m u t . e d u . c n,{ }^{d}$ \\ 2014110804@xmut.edu.cn, ${ }^{\mathrm{e}} 308282534 @ q q . c o m$
}

Keywords: Flywheel bolt; Fatigue fracture; ISG motor; Hybrid bus.

Abstract. Using tool such as torque wrenches, air guns, speed sensors and bolt fastening analyzer, the causes of flywheel bolt fracture of ISG motor was analyzed, respectively from the fixed structure of hybrid bus, tightening performance of bolt and clutches shock characteristics. The results show that lack of tightening torque and excessive torque occurred from clutches shock were the major causes of over-fatigue about flywheel bolt for hybrid bus. The solutions were proposed to prevent the connecting fracture of flywheel bolt, included using level 10.9 Hexagon bolt to increase the tensile strength, and using torque wrench to reset torque value, and insuring clutches engagement synchronously to reduce torque shocks.

\section{Introduction}

One hybrid bus has the ISG series-parallel power system. The specification of the flywheel retaining bolt about ISG motor is M14×2. The performance level is 8.8 . The assembly torsion is $180 \mathrm{~N} \cdot \mathrm{m}$. The material is $40 \mathrm{Cr}$ steel. In the process of comprehensive road test, the clutch driven platen burned after about $15000 \mathrm{~km}$. We find the fact that two fixed bolts (total number is 10) part connected to the second flywheel and the rotor shaft of the ISG motor, and the friction surface of the second flywheel wear badly. To find the causes of the bolts fracture and prevent it from happening again, we analyzed and proposed improvement measures from the aspects such as fixed structure of the flywheel, the performance of bolt tightening, clutch engagement and shock[1].

\section{ISG series-parallel power system}

The structure of ISG series-parallel power system is shown as fig.1. As the main control unit, HCU arrange the distribution and the functional command of various components. ISG motor and drive motor is controlled by the frequency converter.

Engine flywheel (the first flywheel) is connected to the front of ISG motor rotor shaft by torsional vibration damper. There exists the second

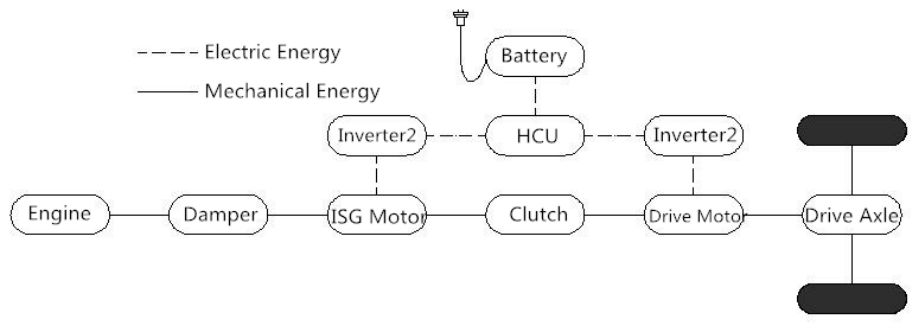

Fig.1 The structure of the ISG series-parallel power system flywheel at the backend of ISG motor rotor shaft which is connected with the front of drive motor rotor shaft by the push type diaphragm spring clutch. Output flange lying in the backend of the drive motor rotor shaft and connecting to the drive shaft could drive the vehicle by the rear axle assembly.

The speed to be as node in ISG hybrid power system divided into the following five kinds of working mode[2] :

a. Pure electric drive mode. When the speed of the car is under $22 \mathrm{~km} / \mathrm{h}$, the clutch disengages and the vehicle is driven by the drive motor instead of engine. Don't start the engine and be in the off state when the battery SOC is more than $50 \%$. 
b. Tandem drive mode. When the speed of the car is under $22 \mathrm{~km} / \mathrm{h}$, the clutch disengages and the vehicle is driven by the drive motor instead of engine. Start the engine and make the ISG motor generate electricity for battery charge when the battery SOC is no larger than $50 \%$.

c. Parallel drive mode. When the speed is more than $22 \mathrm{~km} / \mathrm{h}$, the clutch will be engaged. If the speed is lower than $45 \mathrm{~km} / \mathrm{h}$, engine and drive motor drive the vehicle driving simultaneously.

d. Engine driven model. If the speed is higher than $45 \mathrm{~km} / \mathrm{h}$, the vehicle is driven by engine rather than drive motor.

e. Braking mode. When the signal of breaking or loosing accelerograph comes with battery having no overvoltage, the drive motor through the counter torque could convert kinetic energy into electrical energy for battery charge.

Among them, the clutch will be engaged when the car is the parallel drive mode, the engine drive mode or the braking mode with the speed of over $22 \mathrm{~km} / \mathrm{h}$.

\section{Causes analysis}

Fracture analysis It is the macro appearance of fracture of the fracture bolt as shown Fig.2. The section of two bolts has rust marks, the corrosion of fracture bolt 1 is more serious than fracture bolt 2 . So it can be inferred that bolt 1 would fracture before bolt 2. The final fracture area of two bolts would be small proportion. The results indicate that the bolt force relative to the bolt bearing capacity is not great. Loosening at the fracture of the bolts may results from fatigue fracture [3].

The analysis of tightening performance According to the working standard of the flywheel assembly

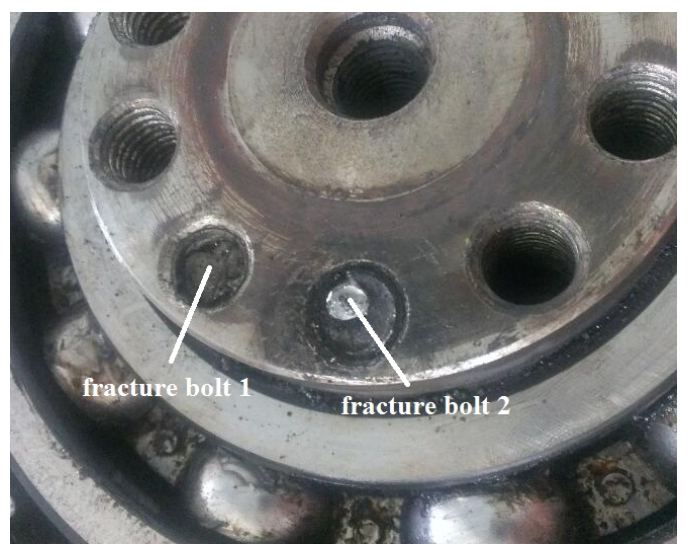

Fig.2 Fracture bolt process, consulting mechanical properties about at the 8.8 level of bolt tightening torque table, we could make sure that the torque of bolt tightening is $180 \mathrm{Nm}$. Referring to industry standard "QC/T518-1999 automotive threaded fasteners tightening torque specification"[4], we see that 180 $\mathrm{Nm}$ about the tightening torque meets the standards.

We applied torque wrench to sample the remove torque in the same batch of ISG motor flywheel fixed bolt and recorded the maximum reading of torque wrench when screwing the bolt, as shown table 1:

Table 1 the maximum reading of the torque wrench when the bolt is screwed out (Unit:Nm)

\begin{tabular}{ccccccccccc}
\hline Bolt number & 1 & 2 & 3 & 4 & 5 & 6 & 7 & 8 & 9 & 10 \\
\hline $\begin{array}{c}\text { Maximum reading of } \\
\text { torque wrench }\end{array}$ & 146 & 151 & 178 & 163 & 148 & 161 & 148 & 154 & 162 & 168 \\
\hline
\end{tabular}

Thread locking glue makes the flywheel bolt locknut. According to practical experience, the removal torque of the bolt is larger than tightening torque. From the table 1 we know that the remove torque of the bolt is less than $180 \mathrm{Nm}$ which Standard Operating Procedure rules, and value of number is in a large scale. It can be concluded that the tightening torque is also less than $180 \mathrm{Nm}$ which Standard Operating Procedure rules. After screening, we find that the jackhammers are used to tighten bolts in the working sites of the flywheel assembly. Sometimes several jackhammers attatched to the same source gas work simultaneously although the pressure of source gas about jackhammers meets the requirements. Then the maximum output torque of the jackhammers would decrease and fluctuate, resulting in the fact that the actual tightening torque of bolts is far less than $180 \mathrm{Nm}$ which Standard Operating Procedure rules. 
The fixed structure of flywheel It is the fixing structure of the flywheeel as shown in fig.3. From the figure, we can realize that the locating spigot of the flywheel assembles with the ISG motor radially and centringly. The axial end face presses against the bearing inner race. It is fixed with the motor shaft by the bolt, and there is some space between the root end face of flywheel pilot flange and the end face of motor shaft. The flywheel material is cast iron. The material of ISG motor shaft is 42CrMo steel.

Supposing that the large diameter of the ring contact surface which is connected by the bolt is $\mathrm{D}_{1}$ and the minor diameter is $\mathrm{D}_{2}$. Friction coefficient is $\mu$. Pressure $\mathrm{F}$ uniformly distributes on the contact surface.

So, friction torque

$$
T_{f}=\int_{R_{1}}^{R_{2}} \frac{\mu \mathrm{F}}{\pi\left[\left(\frac{D_{1}}{2}\right)^{2}-\left(\frac{D_{2}}{2}\right)^{2}\right]} \times 2 \pi r^{2} d r=\frac{\mu \mathrm{F}}{\left[\left(\frac{D_{1}}{2}\right)^{2}-\left(\frac{D_{2}}{2}\right)^{2}\right]} \cdot \frac{2}{3}\left[\left(\frac{D_{1}}{2}\right)^{3}-\left(\frac{D_{2}}{2}\right)^{3}\right]
$$

Among them: $\mathrm{F}$ equals the sum of pre-tightening force of all flywheel bolts.

$F=10 \times \frac{M}{k d}$

M equals the tightening torque of the bolt.

$k$ equals torque coefficient.

$d$ equals the nominal diameter of the bolt.

so:

$$
T_{f}=\frac{10 \mu M}{\operatorname{kd}\left[\left(\frac{D_{1}}{2}\right)^{2}-\left(\frac{D_{2}}{2}\right)^{2}\right]} \cdot \frac{2}{3}\left[\left(\frac{D_{1}}{2}\right)^{3}-\left(\frac{D_{2}}{2}\right)^{3}\right]
$$

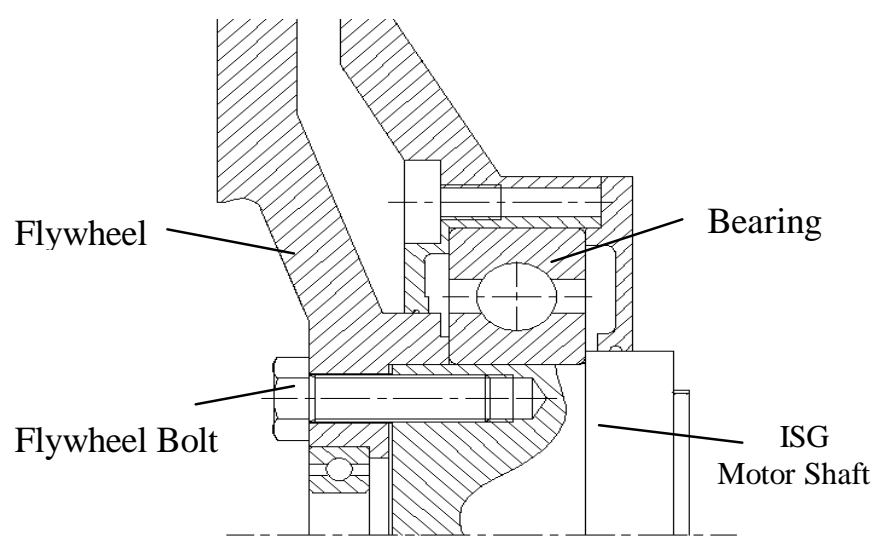

Fig.3 The fixed structure of the flywheel

From technical drawings, D1=116mm , D2 $=100 \mathrm{~mm}, \mathrm{~d}=14 \mathrm{~mm}$.

Because the axial end face presses against the bearing inner race. Bearing grease works and contact surface has grease. Assuming that the maximum static friction force is equal to sliding friction, according to the table of materials commonly used, the friction coefficient of collect $\mu$ equals $0.1[7]$.

According to practical experience, $\mathrm{k}$ value is in the range of $0.100-0.450$ and it is obtained by experiment means. Here we still retain $\mathrm{k}$.

When $\mathrm{M}$ is equal to $180 \mathrm{Nm}, T_{f}$ is $695.56 / \mathrm{k}(\mathrm{Nm})$, when $\mathrm{M}$ equals $140 \mathrm{Nm}, T_{f}$ is $541.00 / \mathrm{k}(\mathrm{Nm})$.

The engine type of the vehicle is YC6J220-42 whereas the flywheel is J41DC-1005361. From the technical drawings, $\mathrm{R}_{2}=61.1 \mathrm{~mm}, \mathrm{R}_{1}=26 \mathrm{~mm}, d=14 \mathrm{~mm}$. By the formula

$$
T_{f}=\int_{R_{1}}^{R_{2}} \frac{\mu \mathrm{F}}{\pi\left[\left(\frac{D_{1}}{2}\right)^{2}-\left(\frac{D_{2}}{2}\right)^{2}\right]} \times 2 \pi r^{2} d r=\frac{\mu \mathrm{F}}{\left[\left(\frac{D_{1}}{2}\right)^{2}-\left(\frac{D_{2}}{2}\right)^{2}\right]} \cdot \frac{2}{3}\left[\left(\frac{D_{1}}{2}\right)^{3}-\left(\frac{D_{2}}{2}\right)^{3}\right]
$$

We calculate that the friction torque of the engine flywheel and crankshaft $T_{f}=1344.43 / \mathrm{k}(\mathrm{Nm})$. It indicates that the friction torque of the flywheel ISG motor $T_{f}$ is far less than the engine flywheel $T_{f}$ '. It is easy to cause the relative sliding between the flywheel and the ISG motor shaft because reserve coefficient is superlow when transfering the engine torque. 
The impact of clutch engaging As described previously, the clutch will be engaged when the car is the parallel drive mode, the engine drive mode or the braking mode with the speed of over $22 \mathrm{~km} / \mathrm{h}$.

The return of the clutch booster cylinder makes the clutch engage when the power system is from the pure electric drive mode to parallel drive mode. Theoretically the speed of the drive motor should be consistent with engines' but the fact is opposite due to the jat lag of the clutch engagement, delay of the CAN communication and the sampling precision of speed sensor. The difference of rotation speeds will come about torsional pulse for the flywheel with the clutch engaging. Finally the torsional pulse will be shear force in the flywheel bolt. The shear force will be bigger when the torsional pulse is greater with the difference of rotation speeds largening.

\section{Solutions}

From the above analysis, we may solve the problem about the fracture of the flywheel bolt from two aspects. One is to strengthen the performance of bolt locking, and another is to improve the friction torque between the flywheel and the ISG motor.

10.9 hexagon bolt possessing flange surface and fine teeth The surface of flange plates containing flange teeth on the 10.9 hexagon bolt could loosen. Anti-looseness effect is better coordinated with anaerobic thread-locking Adhesives[5]. Performance level from 8.8 to 10.9 will improve the tensile strength. The pitch from the coarse teeth $2.0 \mathrm{~mm}$ to fine teeth $1.5 \mathrm{~mm}$ can further improve the locking effect[8]. Referring to industry standard "QC/T518-1999 automotive threaded fasteners tightening torque specification", tightening torque could ascend to $210 \mathrm{Nm}$, even to $235 \mathrm{Nm}$.

Using torque wrench operation Torque wrench can be set torque. When torque reaches the set value, wrench will raise the sound of "clicking". It indicates that torque is up to the standard. Therefore we wouldn't make air pressure of jackhammer not enough and torque insufficient. To improve the efficiency, we can use the jackhammer to lock the bolt to a certain degree firstly and then employ a torque wrench to tighten.

Improving the fixed structure of the flywheel Eliminate the gap between the root end face of flywheel pilot flange and the end face of motor shaft with the lathe cutting the end face of the existing flywheel $1.5 \mathrm{~mm}$. After improving the fixed structure of the flywheel, the root end face of flywheel pilot flange contacts with the end face of motor shaft. There is no grease in the contact surface compared to the structure in the bearing inner ring before improving. The fact that the surface roughness of the motor shaft end face is greater than the surface roughness of the bearing inner ring improves the coefficient of friction. And simultaneously the maximum diameter and minor diameter of the ring contact surface are changed, $\mathrm{D}_{1}=100 \mathrm{~mm}, \mathrm{D}_{2}=45 \mathrm{~mm}$.

By the formula:

$$
T_{f}=\frac{10 \mu M}{\operatorname{kd}\left[\left(\frac{D_{1}}{2}\right)^{2}-\left(\frac{D_{2}}{2}\right)^{2}\right]} \cdot \frac{2}{3}\left[\left(\frac{D_{1}}{2}\right)^{3}-\left(\frac{D_{2}}{2}\right)^{3}\right]
$$

Eq:

Among them: $\mu=0.2, \mathrm{M}=210 \mathrm{Nm}$.

$$
T_{f}=1139.66 / \mathrm{k}(\mathrm{Nm})
$$

The synchronous joint of clutch The speed of the ISG motor is the same as the speed of the engine as the engine is connected with ISG motor through the torsional vibration damper. Motor controller acquisition speed sensor which responds faster is more accurate than ECU collecting engine speed signal for rotate speed. Before the clutch engagement, HCU constantly compares the ISG motor speed 
and drive motor speed in the clutch booster cylinder action process and change speed to reduce the torsional impact due to speed difference.

\section{Improvement result conclusions}

After proposing solution, the three improvements including 4.1, 4.2, 4.3 are carried out in the mass production of ISG motors. We do a survey about the improved ISG motor on the market and the results indicate that the phenomenon about the fracture of the flywheel bolt has not yet come after run 250000 kilometers.

To prevent the flywheel bolt of motors from parting on the hybrid electric bus ISG, we analyzed and proposed improvement measures from the aspects such as flywheel fixed structure, performance of bolt tighten, clutch engagement and shock. The following conclusions were drawn:

1) Fatigue fracture occurred in the fixed bolt of the flywheel.

2) The reliability is low if we use jackhammers to screw down the bolt. And it is easy to cause the bolt pre-tightening force insufficient.

3) The design of flywheel fixed structure is not reasonable. The friction torque between the parts is small in the process of employment. The sliding friction between parts makes the bolt loose, resulting in fatigue fracture.

\section{Acknowledgements}

This study was financially supported by the Research and Development Project of State High Technology of China ('863 Project', 2012AA111105) and the Fujian Science and the Technology Project of China $(2016 \mathrm{H} 2003)$.

\section{Reference}

[1] Li Ming, Hu Wei, Li Guang, et al. Promotion of reliability flywheel bolt connection[J]. Automotive practical technology, 2016(3):120-124.

[2] Ye Xianjun, Zhang Bingli, Wang Xizhen. ISG hybrid power system structural analysis and design applications[C]// Dr Anhui energy conservation and emissions reduction technology BBS. 2007.

[3] Pang Yuan, Zhang Xiaorong, Chen Peilei. Fracture Analysis of brake mounting bolts[J]. Testing: Physical Volume, 2014, 50(3).

[4] QC/T518-1999, Automotive threaded fastener tightening torque specification[S]. Beijing: State Administration of Machinery Industry,1999.

[5] Meng Ke, Xue Jian, Lie Hailiang, et al. Anaerobic thread locking glue in the mechanical assembly process[J]. Mechanical Engineers, 2013(8):221-222.

[6] Wang Peng, Chenan Sheng, Zhang Kuaiwu, et al. Experimental Study of bolt torque Coefficient[J]. Experimental Mechanics, 2013, 28(3):307-313.

[7] Wang Xiaotian. Metal Materials Science[M]. Beijing: State Administration of Machinery Industry, 1987.

[8] Chen Shaorong. Understanding the mechanical properties of bolts[J]. Fastener Technology, 2008(4):10-12. 